World Applied Sciences Journal 19 (1): 83-88, 2012

ISSN 1818-4952;

(C) IDOSI Publications, 2012

DOI: 10.5829/idosi.wasj.2012.19.01.2758

\title{
Mathematical Modeling of Heat Transfer Processes of Coal Waste Combustion in a Chamber of Automated Energy Generating Complex
}

\author{
S.P. Mochalov, S.N. Kalashnikov and P.S. Mochalov \\ Federal State Budget Educational Institution of High Education \\ "Siberian State Industrial University, Kirova street 42, 654007 Novokuznetsk, Russia
}

\begin{abstract}
The automated energy generating complex allows to obtain heat energy from water coal-water slurry fuel (WCF) that is a mixture of fine coal particles from coal enrichment wastes with water. The mixture under the pressure is blown into the swirl chamber through special sprayers. The received heat energy is used in different ways. One of the important issues is to estimate the heat losses through the walls of this chamber. In this research paper we solved the boundary problem of mathematical physics to estimate the temperature of fields in the walls of the swirl chamber. The obtained solution allows us to estimate the heat losses through the walls of the swirl chamber. The task of mathematical physics is solved by a numerical finite-difference method. The methods of solving this problem can be used in the calculation of temperature fields and evaluation of heat losses in other thermal power units.
\end{abstract}

Key words: Heat transfer $\cdot$ Heat conduction equation $\cdot$ Boundary conditions $\cdot$ The heat transfer coefficient - Temperature distribution

\section{INTRODUCTION}

In 2012, municipal and industrial enterprises, as well as other companies and organizations related to energy, must carry out the so-called energy audit to find out how much energy they consume and at the same time - how much they are losing due to the low degree of control and assessment of energy consumption and energy losses. And depending on the results of energy audit they must develop a set of energy-saving measures. This is particularly true for enterprises and industrial structures, which themselves produce energy in one form or another and should prevent its loss. In this paper we investigate the process of heating of the combustion chamber wall in the automated power generating complex in which the WCF is burned in order to estimate the energy loss through the wall.

Water-coal fuel can be used as a substitute for conventional fuels such as oil, gas and coal in the boiler and heating units of a thermal power station and it should be considered as a link in the chain of coal mining, utilities / power generation, solutions of construction problems: reduction of fuel costs, coal waste disposal (sludge), the production of heat / electricity, a source of high-value ash, which can be considered as a separate commercial product. WCF is used as a clean and inexpensive source of heat and fuel for a modern power system [1-5].

The main advantages of WCF are the reduction of fuel costs compared to fuel oil and gas, emissions reduction, as well as the technological ease of use of coal in liquid form. WCF is burned in combustion chambers of all types: flare and flare-swirl, in a boiling layer with one stage, in a boiling layer with two stages and others. Water-coal fuel allows businesses to reduce fuel costs for the production of heat and electrical energy by replacing a significant portion of the consumpted fuel oil and (or) gas. WCF is ecologically compatible due to the fact that the elimination of accidental spills of fuel does not require any special measures - it is enough to wash the contaminated area with water.

Taking into account the fact that WCF is a clean and inexpensive source of heat, a very urgent task is to preserve the received energy from this fuel and this in turn leads to the need to solve one more significant problem of adequate evaluation of the heat losses through the elements of industrial or semi-industrial

Corresponding Author: S.P. Mochalov, Federal State Budget Educational Institution of High Education "Siberian State Industrial University, Kirova street 42, 654007 Novokuznetsk, Russia. 
systems designed for WCF combustion. The solution of this task will enable the care of the received energy and provide recommendations for choosing the most effective thermal insulating materials.

In this paper we consider the version of the flareswirl combustion chamber and solve the problem of evaluation of heat loss through the wall of the combustion chamber.

Formulation and Solution of the Problem: Swirl chamber for WCF burning has a geometric form of a rectangular parallelepiped with a cavity inside where CWF burning takes place. To estimate the heat flows and heat losses from the swirl combustion chamber in this paper in terms of equality of heat flows through the wall of the swirl combustion chamber it is proposed to calculate them for the combustion chamber, in which the internal cavity is a rectangular parallelepiped, internal surface area is equal to the inside surface area of the actual combustion chamber. The calculation of thermophysical properties is carried out in Cartesian coordinates with three-dimensional approximation.

For the calculation of temperature fields in the wall of the swirl chamber methods of the theory of heat transfer are used $[6,7]$. Dynamics of temperature fields change in the walls of the swirl combustion chamber with an internal cavity in the form of a rectangular parallelepiped in Cartesian coordinates $x, y, z$ is described by the heat equation [8].

$$
c \rho \frac{\partial t}{\partial \tau}=\frac{\partial}{\partial x}\left(\lambda \frac{\partial t}{\partial x}\right)+\frac{\partial}{\partial y}\left(\lambda \frac{\partial}{\partial y}\right)+\frac{\partial}{\partial z}\left(\lambda \frac{\partial}{\partial z}\right),
$$

Where $c$ - specific heat, $\mathrm{J} /\left(\mathrm{kg} \cdot{ }^{\circ} \mathrm{C}\right), \rho$ - density, $\mathrm{kg} / \mathrm{m}^{3}$, $\lambda$ - coefficient of thermal conductivity of materials of the wall of adiabatic swirl chamber, $\mathrm{W} /\left(\mathrm{m} \bullet{ }^{\circ} \mathrm{C}\right), \tau$ - time with the boundary conditions of the third kind

$$
\lambda \frac{\partial t}{\partial n_{k}}=\alpha_{k}\left(t_{k}-t\right),
$$

Where $n_{k}$ - the normal to the corresponding $k$-section of the boundary of the swirl chamber, both inside and outside the chamber;

$t=$ Calculating temperature of the wall at the boundary areas, ${ }^{\circ} \tilde{N}$;

$t_{k}=$ Temperature of the environment from the side of $k$-boundary area;

$\alpha_{k}=$ Heat-transfer coefficient of the corresponding $k$ area of the combustion chamber wall

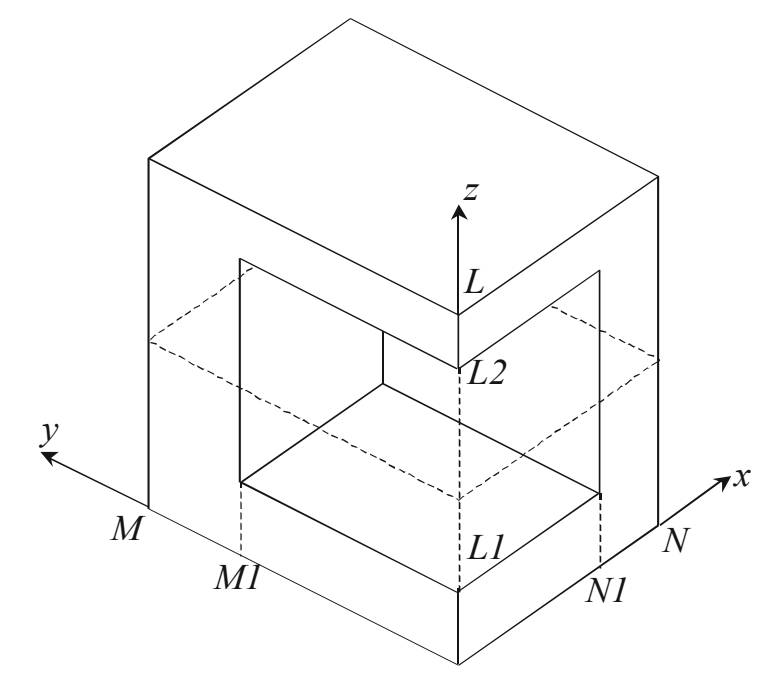

Fig. 1: Computational domain for solution of the heat equation

Equation (1) is supposed to be solved with the finite difference method. Finite difference method is widely known and the simplest method of interpolation. Its essence is to replace the differential operators of the equation by difference operators, that reduces the solution of the differential equation to the solution of its differential analog, i.e. to construct the finite-difference scheme.

Geometrically, the swirl chamber is considered in a three-dimensional approximation. Figure 1 shows a quarter of the chamber, which is chosen as the computational domain because of the geometric symmetry of the problem.

The case is considered when the wall of the swirl combustion chamber consists of two materials with their individual thermophysical properties: specific heat of $c_{l}=0.94 \mathrm{~kJ} /\left(\mathrm{kg} \bullet{ }^{\circ} \mathrm{C}\right)$, density $\rho_{l}=1875 \mathrm{~kg} / \mathrm{m} 3$, heat-transfer coefficient $\lambda_{I}=1.28 \mathrm{~W} /\left(\mathrm{m} \cdot{ }^{\circ} \mathrm{C}\right)$ for chamotte brick ShB-5 from the internal volume of the combustion chamber and $c_{2}=0,84 \mathrm{~kJ} /\left(\mathrm{kg} \cdot{ }^{\circ} \mathrm{C}\right), \rho_{2}=46 \mathrm{~kg} / \mathrm{m} 3$,

$\lambda_{2}=0,036 \mathrm{~W} /\left(\mathrm{m} \cdot{ }^{\circ} \mathrm{C}\right)$ for Isover (thermal insulation material) from the external environment.

Chamotte is a refractory clay, kaolin, burned up to the loss of ductility, removal of chemically bound water and brought to a certain degree of sintering. This name is also applied to other raw materials used for production of refractories, burned up to sintering of the clay mixed with powders and stabilization of material properties. According to the materials used there are highalumina, alumina, zircon chamotte, brick made ?from chamotte clay. 


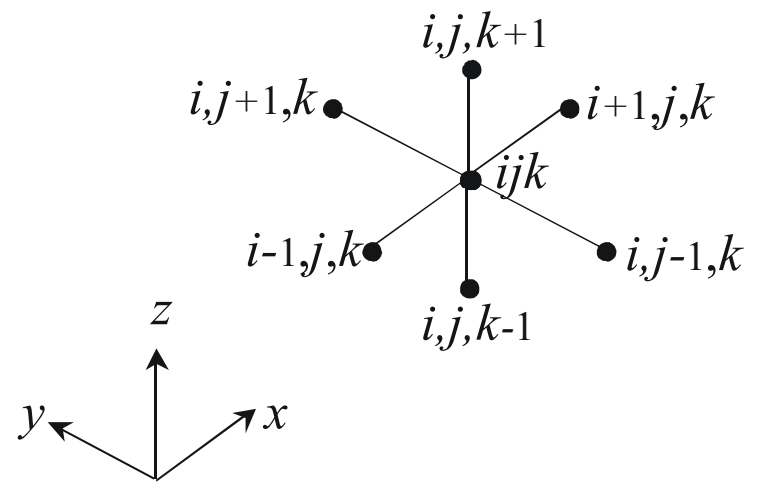

Fig. 2: Difference template for constructing the finite scheme

Isover is a world leader in manufacture of heat insulation material from mineral wool structure, it is the insulation material in coils and slabs from mineral wool on the basis of the highest quality fiberglass, which is a produced in accordance with the patented fiber formation from natural materials: sand, soda, limestone and provides an effective heat insulation and soundproofing for buildings of various purposes and production units in various fields.

Consider the finite-difference $3 D$-approximation $[9$, 10] of differential operators with respect to time $\tau$ and the coordinates $x, y, z$ in equation (1).

The bulk area of the swirl combustion chamber wall is replaced by a three-dimensional mesh area with uniform discretization steps $\Delta x, \Delta y, \Delta z$ along the corresponding coordinate axes. Temperature $t$ inside and at the wall boundary of the swirl combustion chamber is replaced by discrete values $t_{i j k}$ in the nodes of three-dimensional mesh area. Figure 2 shows the numbers of nodes on the corresponding coordinate axis at the boundaries of the computational domain.

Approximation is made by means of a 7-point three-dimensional template presented in Figure 2, which shows the numbering of nodes of a three-dimensional pattern on the coordinates $x, y, z$ respectively.

To the node of the mesh area with number $i j k$ eight elementary volumes ajoin with value of $\Delta V=\Delta x \cdot \Delta y \bullet \Delta z$, in the center of which there are eight auxiliary nodes of the mesh area with fractional values of indices $i \pm \frac{1}{2}, j \pm \frac{1}{2}, k \pm \frac{1}{2}$.

The differential equation (1) is approximated by a system of finite difference equations for the values of the temperature of the swirl combustion chamber wall in the nodes with integer values of the indices $i j k$. The values of the thermophysical parameters $c, \rho, \lambda$ of wall materials, including different ones and are given in units of fractional values of the indices $i \pm \frac{1}{2}, j \pm \frac{1}{2}, k \pm \frac{1}{2}$, i.e. within each elementary volume, obtained by partitioning the original domain at the coordinates $x, y, z$.

Finite-difference approximation of equation (1) using the finite difference explicit scheme can be presented as following:

$$
\begin{aligned}
& c_{i j k} \rho_{i j k} \frac{\tilde{t_{i j k}}-t_{i j k}}{\Delta \tau}=\frac{1}{\Delta x}\left(\lambda_{i+\frac{1}{2}, j, k} \frac{\left(t_{i+1, j, k}-t_{i j k}\right)}{\Delta x}-\lambda_{i-\frac{1}{2}, j, k} \frac{\left(t_{i j k}-t_{i-1, j, k}\right)}{\Delta x}\right)+ \\
& +\frac{1}{\Delta y}\left(\lambda_{i, j+\frac{1}{2}, k} \frac{\left(t_{i, j+1, k}-t_{i j k}\right)}{\Delta y}-\lambda_{i, j-\frac{1}{2}, k} \frac{\left(t_{i j k}-t_{i, j-1, k}\right)}{\Delta y}\right) \\
& +\frac{1}{\Delta z}\left(\lambda_{i, j, k+\frac{1}{2}} \frac{\left(t_{i, j, k+1}-t_{i j k}\right)}{\Delta z}-\lambda_{i, j, k-\frac{1}{2}} \frac{\left(t_{i j}-t_{i, j, k-1}\right)}{\Delta z}\right),
\end{aligned}
$$

where - $\underset{t_{i j k}}{\sim}$ - temperature value in the mesh nodes at the next time step.

Thus, it is necessary to estimate the values of thermophysical parameters $\rho_{\mathrm{ijk}}$ and $c_{\mathrm{ijk}}$ in the basic nodes of the mesh area and assessment of values $\lambda i \pm \frac{1}{2}, j, k$, $\lambda_{i, j, k \pm \frac{1}{2}}, \lambda_{i, j \pm \frac{1}{2}, k}$ with values $\rho_{i \pm \frac{1}{2}, j \pm \frac{1}{2}, k \pm \frac{1}{2}}, c_{i \pm \frac{1}{2}, j \pm \frac{1}{2}, k \pm \frac{1}{2}}$ and $\lambda_{i \pm \frac{1}{2}, j \pm \frac{1}{2}, k \pm \frac{1}{2}}$ defined in subsidiary nodes of this area with fractional values of the indices.

Assessment of values $\rho_{\mathrm{ijk}}$ with the help of densities values of eight adjacent elementary volumes is realized as the average density values of this elementary volumes using the relation:

$$
\rho_{i j k}=\frac{\sum_{\alpha= \pm \frac{1}{2}} \sum_{\beta= \pm \frac{1}{2}} \sum_{\gamma= \pm \frac{1}{2}} \rho_{i+\alpha, j+\beta, k+\gamma}}{8}
$$

based on the approximation that this eight elementary volumes, even being the representatives of materials with different densities, together form a homogeneous material with the corresponding density.

Assessment of values $c_{\mathrm{ijk}}$ with the help of values of specific heat capacities and densities of eight adjacent elementary volumes can be presented by the relation: 


$$
c_{i j k}=\frac{\sum_{a= \pm \frac{1}{2}} \sum_{\beta= \pm \frac{1}{2}} \sum_{\gamma= \pm \frac{1}{2}} \rho_{i+a, j+\beta, k+\gamma} c_{i+a, j+\beta, k+\gamma}}{\sum_{a= \pm \frac{1}{2}} \sum_{\beta= \pm \frac{1}{2}} \sum_{\gamma= \pm \frac{1}{2}} \rho_{i+a, j+\beta, k+\gamma}}
$$

based on the approximation that this eight elementary volumes, even being the representatives of materials with different specific heat capacities and densities and having received individually a certain amount of heat, together form a homogeneous material with the corresponding specific heat, which obtained the amount of heat equal to the sum received by all the elementary volumes of heat.

Estimation of the coefficient values of thermal conductivity in the required nodes is carried out by using the values of thermal conductivity of elementary volumes in the following way:

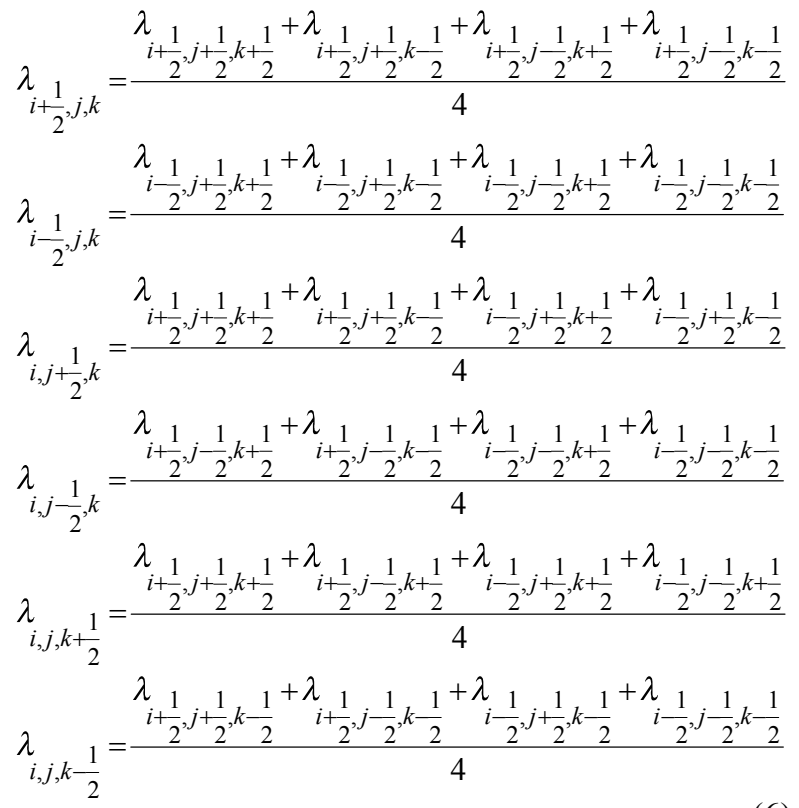

Approximation of boundary conditions of the $3^{\text {rd }}$ kind $\lambda \frac{\partial t}{\partial n}=\alpha_{k}\left(t_{k}-t\right)$ on the corresponding boundary area is carried out by using the three-point approximation of the depth of the derivative along the normal to the corresponding section of the border with the help of the relation

$$
\lambda_{k} \frac{3 t_{B}-4 t_{B-1}+t_{B-2}}{2 \Delta n}=\alpha_{k}\left(t_{k}-t_{B}\right)
$$

As a result there is the following relation to calculate the temperature at the corresponding boundary:

$$
t_{B}=\frac{2 \alpha_{k} \Delta x t_{k}+\lambda_{k}\left(4 t_{B-1}-t_{B-2}\right)}{2 \alpha_{k} \Delta x+3 \lambda_{k}}
$$

In various parts of the computational domain there are the following relations for calculation of the temperature at the boundary:

border 1 - the inner boundary (plane $x 0 z$ )

$$
t_{i, 0, k}=\frac{4 t_{i, 1, k}-t_{i, 2, k}}{3}
$$

border 2 - inner boundary (plane $y 0 z$ )

$$
t_{0, j, k}=\frac{4 t_{1, j, k}-t_{2, j, k}}{3}
$$

border 3 - "bottom outside" (plane $x 0 y$ )

$$
t_{i, j, 0}=\frac{2 \alpha_{1} \Delta z t_{2}+\lambda_{2}\left(4 t_{i, j, 1}-t_{i, j, 2}\right)}{2 \alpha_{1} \Delta z+3 \lambda_{2}}
$$

border 4 - "top outside" (plane $x 0 y$ )

$$
t_{i, j, L}=\frac{2 \alpha_{1} \Delta z t_{2}+\lambda_{2}\left(4 t_{i, j, L-1}-t_{i, j, L-2}\right)}{2 \alpha_{1} \Delta z+3 \lambda_{2}}
$$

border 5 - "on the top inside the chamber"

$$
t_{i, j, L 1}=\frac{2 \alpha_{4} \Delta z t_{1}+\lambda_{1}\left(4 t_{i, j, L 1-1}-t_{i, j, L 1-2}\right)}{2 \alpha_{4} \Delta z+3 \lambda_{1}}
$$

border 6 - boundary "bottom inside"

$$
t_{i, j, L 2}=\frac{2 \alpha_{4} \Delta z t_{1}+\lambda_{1}\left(4 t_{i, j, L 2+1}-t_{i, j, L 2+2}\right)}{2 \alpha_{4} \Delta z+3 \lambda_{1}}
$$

border 7 - "on the side along $y$ "

$$
t_{i, M, k}=\frac{2 \alpha_{3} \Delta y t_{2}+\lambda_{2}\left(4 t_{i, M-1, k}-t_{i, M-2, k}\right)}{2 \alpha_{3} \Delta y+3 \lambda_{2}}
$$

border 8 - "inside along $y$ "

$$
t_{i, M 1, k}=\frac{2 \alpha_{3} \Delta y t_{1}+\lambda_{1}\left(4 t_{i, M-1, k}-t_{i, M-2, k}\right)}{2 \alpha_{3} \partial \Delta y+3 \lambda_{1}}
$$

border 9 - "on the side along $x$ "

$$
t_{N, j, k}=\frac{2 \alpha_{3} \Delta x t_{2}+\lambda_{2}\left(4 t_{N-1, j, k}-t_{N-2, j, k}\right)}{2 \alpha_{3} \Delta x+3 \lambda_{2}}
$$

border 10 - "inside along $x$ "

$$
t_{N 1, j, k}=\frac{2 \alpha_{4} \Delta x t_{1}+\lambda_{1}\left(4 t_{N 1+1, j, k}-t_{N 1+2, j, k}\right)}{2 \alpha_{4} \Delta x+3 \lambda_{1}}
$$


World Appl. Sci. J., 19 (1): 83-88, 2012

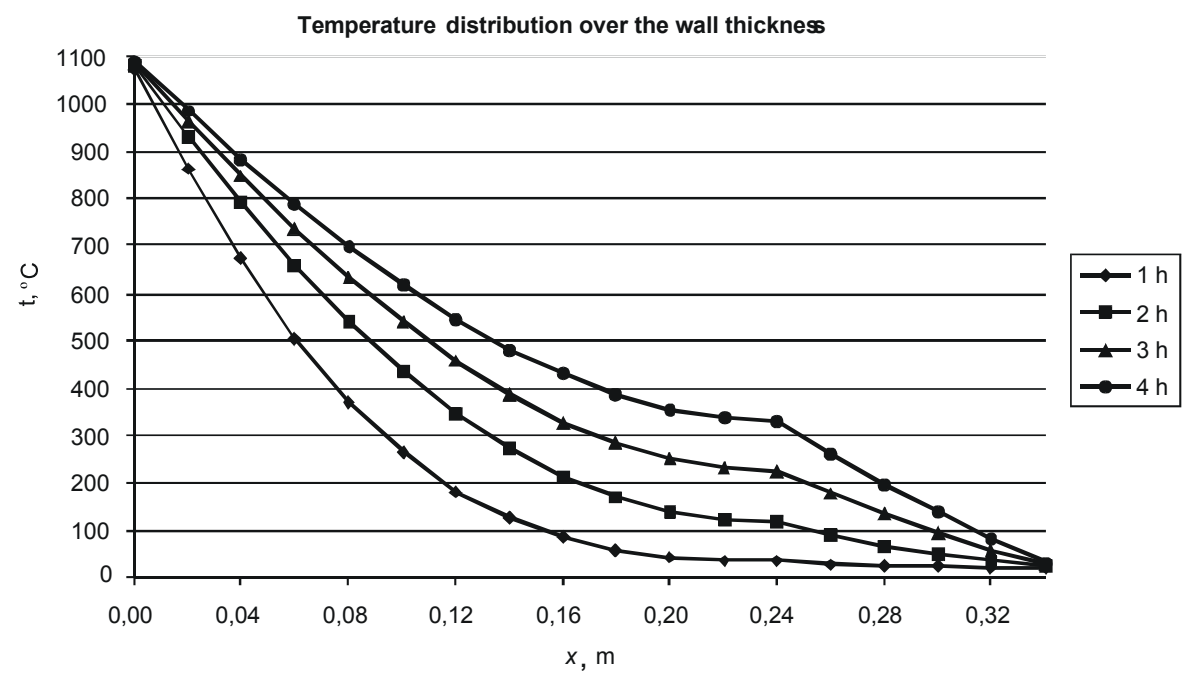

Fig. 3: Graphs of the temperature distribution over the wall thickness of the combustion chamber at $\alpha=5 \mathrm{~W} /\left(\mathrm{m}^{2} \cdot{ }^{\circ} \mathrm{C}\right)$

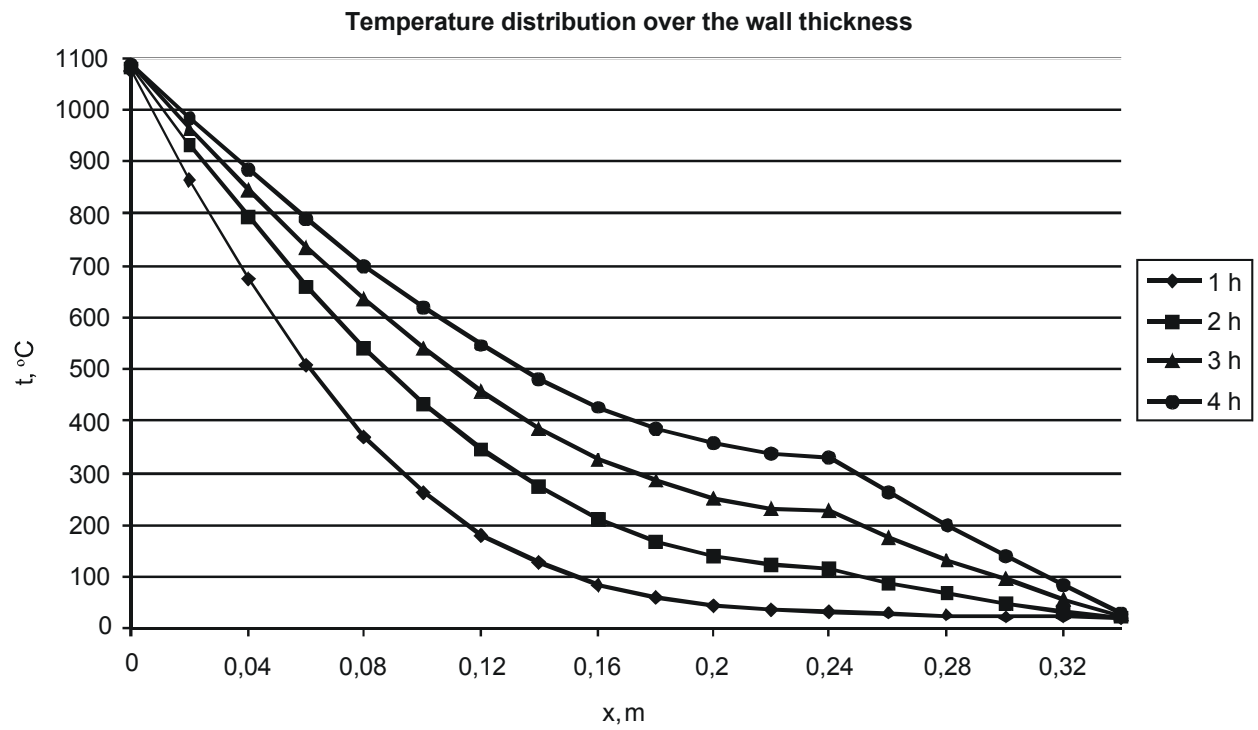

Fig. 4: Graph of the temperature distribution over the wall thickness of the swirl combustion chamber at $\alpha=10 \mathrm{~W} /\left(\mathrm{m}^{2} \bullet{ }^{\circ} \mathrm{C}\right)$

Table 1: Temperature values of the wall of swirl combustion chamber at $\alpha=5 \mathrm{~W} /\left(\mathrm{m}^{2} .{ }^{\circ} \mathrm{C}\right)$

\begin{tabular}{llll}
\hline$x$ & 0 & 0.24 & 0.34 \\
\hline $1 \mathrm{~h}$ & 1072 & 35 & 20 \\
$2 \mathrm{~h}$ & 1080 & 117 & 24 \\
$3 \mathrm{~h}$ & 1084 & 226 & 31 \\
$4 \mathrm{~h}$ & 1087 & 332 & 38 \\
\hline
\end{tabular}

Table 2: Temperature values of the wall of swirl combustion chamber at $\alpha=10 \mathrm{~W} /\left(\mathrm{m}^{2} \bullet{ }^{\circ} \mathrm{C}\right)$.

\begin{tabular}{lllc}
\hline$x$ & 0 & 0.24 & 0.34 \\
\hline $1 \mathrm{~h}$ & 1072 & 35 & 20 \\
$2 \mathrm{~h}$ & 1080 & 117 & 22 \\
$3 \mathrm{~h}$ & 1084 & 226 & 26 \\
$4 \mathrm{~h}$ & 1087 & 332 & 30 \\
\hline
\end{tabular}

Below are the results of the study on a mathematical model of heat transfer processes in the swirl adiabatic combustion chamber in the form of tables 1,2 and graphs (Figures 3,4) of the temperature distribution over the thickness of the sidewall of the chamber in its thinnest point with thickness $0.34 \mathrm{~m}(0.24 \mathrm{~m}$ is chamotte; $0.1 \mathrm{~m}$ is Isover insulation material) for various time points after the start of the swirl combustion chamber ( $1 \mathrm{~h}, 2 \mathrm{~h}, 3 \mathrm{~h}, 4 \mathrm{~h}$ ) and the convection heat transfer coefficient $\alpha$ from the surrounding air with its free movement equal to 5 $\mathrm{W} /\left(\mathrm{m}^{2} \cdot{ }^{\circ} \mathrm{C}\right)$ and $10 \mathrm{~W} /\left(\mathrm{m}^{2} \bullet{ }^{\circ} \mathrm{C}\right)$. The temperature inside the combustion chamber is assumed to be $1100{ }^{\circ} \mathrm{C}$ and the outside air temperature $-20^{\circ} \mathrm{C}$. The tables show the temperature at the inner and outer walls of the swirl adiabatic combustion chamber and at the junction of chamotte and Isover (where $x=0.24 \mathrm{~m}$ ). 
Density $q$ of heat losses at $\alpha=5 \mathrm{~W} /\left(\mathrm{m}^{2} \cdot{ }^{\circ} \mathrm{C}\right)$ after 4 hours of work of the swirl combustion chamber on the side walls is $105 \mathrm{~W} / \mathrm{m}^{2}$.

Density $q$ of heat losses at $\alpha=10 \mathrm{~W} /\left(\mathrm{m}^{2}{ }^{\circ} \mathrm{C}\right)$ after 4 hours of work of the swirl combustion chamber on the side walls is $97 \mathrm{~W} / \mathrm{m}^{2}$.

Conclusions and Recommendations: In this paper we formulated and solved the problem for the estimation of temperature fields in the wall of the swirl combustion chamber during WCF combustion. The solution obtained allows us to estimate the heat losses through the walls of the swirl chamber. The problem is solved by a numerical finite-difference method. This method can be used in the calculation of temperature fields and evaluation of heat losses in other thermal power units.

\section{ACKNOWLEDGEMENTS}

This work is carried out within the project No. 2010218-02-174 by the Governmental Order of the Russian Federation of April 9, 2010 No. 218 "On measures of federal support of cooperation between higher educational institutions and enterprises which realize complex projects of hi-tech production development".

\section{REFERENCES}

1. Baranov, V.M., 2005. Principles of thermal. Tutorial / V.M. Baranov, V.V. Litvinchuk, Khabarovsk: Publisher Dvgups, 82 : ill.

2. Kuznetsov, A.V., S.P. Rudobashta and A.V. Simenko, 2001. Principles of heat engineering, fuel and lubricating materials. - M. Kolos, pp: 248.

3. Lyashkov, V.I., 2005. Theoretical principles of heat engineering: Tutorial. $2^{\text {nd }}$ edition.. M.: Publisher Mashinostroyenye-1, pp: 260.

4. Klimenko, A.V. and V.M. Zorin, Theoretical 2001. principles of heat engineering. - Publisher M.: MPEI, pp: 561.

5. Rudobashta, S.P., 2010. Heat engineering [Text] : Tutorial / S.P. Rudobashta. - M. : KolosS, 2010 (Smolensk). pp: 599. : ill. - (Textbooks and tutorials for students of institutions of higher education). Bibliography.: pp: 588. Index.: pp: 589-592.

6. Introduction to heat transfer. Teodor L. Bergman, Frank P. Incropera, Adrienne C. Lavine, pp: 960.

7. Principles of heat and mass transfer. Teodor Bergman L. Adrienne . Lavine, C. Frenk P. Incropera, pp: 1048.

8. Widder, D.V., 1975. The Heat Equation. - Academic Press, pp: 267.

9. Patenkar, S.V., 2003. Numerical solution of problems of heat conductivity and of convective heat transfer while flowing in channels. - M.: Publisher MPEI, pp: 312.

10. John, C., 2004. Finite Difference Schemes and Partial Differential Equations - Strikwerda, pp: 435. 